\title{
Effects of nitroglycerin, postextrasystolic potentiation, and pacing-induced ischaemia on wall motion in patients with ischaemic heart disease
}

\author{
FRANZ SCHWARZ, ROLAND ENSSLEN, JOCHEN THORMANN, AND \\ MICHAEL SESTO
}

From the Kerckhoff-Klinik, Bad Nauheim, West Germany

The influence of nitroglycerin, postextrasystolic potentiation, and rapid ventricular pacing on total and regional ventricular function was studied in 32 patients with normal ventricular function and in 44 patients with left ventricular asynergy caused by obstructive coronary artery disease. Total ventricular function was assessed by ventriculography and regional ventricular function was analysed by use of 7 hemiaxes. Nitroglycerin increased ejection fraction and decreased left ventricular systolic and end-diastolic pressures in the normally functioning ventricles; apical wall motion increased, while basal wall motion remained unchanged after nitroglycerin in these ventricles. Pressures fell significantly in ventricles with asynergy after nitroglycerin; ejection fraction decreased while wall motion in asynergic areas was inconsistently influenced. Postextrasystolic potentiation augmented ejection fraction by a powerful and homogeneous increase of wall motion in normally functioning ventricles. Asynergic areas and normal areas in diseased ventricles showed identical augmentation of wall motion after a premature beat. Rapid ventricular pacing produced a significant increase in end-diastolic pressure and a fall in ejection fraction in patients with obstructive coronary artery disease. Wall motion in normal areas perfused by arteries with critical stenoses was dramatically depressed after pacing, while asynergic areas and normal areas perfused by normal arteries remained unchanged. The results show that normal contractile behaviour can be detected by postextrasystolic potentiation in asynergic areas, suggesting that some normally perfused muscle exists in these areas. Pacing stress does not further deteriorate function in asynergic areas, which suggests the presence of viable and well perfused muscle (within scar tissue) whose function may not profit from revascularization. Pacing-induced asynergy identifies the functional significance of coronary stenoses and suggests that bypass surgery might be beneficial.

The results of aortocoronary bypass surgery have shown that in some patients with ischaemic heart disease regional wall motion abnormalities may be reversible after restoration of blood flow. From this observation the hypothesis was derived that ventricular asynergy in such cases may result from chronic ischaemia of viable heart muscle (Chatterjee et al., 1973). Reversibility of asynergy was shown after administration of nitroglycerin and after postextrasystolic potentiation (Sniderman et al., 1974; McAnulty et al., 1975; Banka et al., 1975; Klausner et al., 1975). The diagnosis of reversible asynergy is clinically important since improvement of wall motion after aortocoronary bypass surgery seems to correspond to the preoperative response of wall motion induced by

Received for publication 26 April 1976 nitroglycerin (Helfant et al., 1974) or postextrasystolic potentiation (Hamby et al., 1975). The aim of this study is to compare the changes of wall motion in left ventricular asynergy induced by nitroglycerin, postextrasystolic potentiation, and pacing-induced ischaemia. These interventions should help to answer the question as to whether chronic ischaemia of viable heart muscle exists in asynergic areas caused by coronary artery disease.

\section{Patients}

Studies were performed in 76 patients undergoing diagnostic left heart catheterisation for assessment of ischaemic heart disease. Each patient gave informed consent for the study. Apart from the control group there was a selection process in so 
far as only patients with ischaemic heart disease with ventricular asynergy (as defined below) were considered. No medical treatment was given during the 2 days before catheterisation.

The 76 patients were divided into 3 groups: (1) Group 1 (control group) consisted of 32 patients, without valvular or congenital heart disease. Coronary angiography and ventriculography was normal in these patients. There were 9 women and 23 men with a mean age of $43 \cdot 1 \pm 9 \cdot 7$ (SD) years.

(2) Group 2 consisted of 19 patients with ischaemic heart disease. There were 18 men and 1 woman with a mean age of $49.7 \pm 5.9$ years. Fourteen patients had more than 85 per cent luminal narrowing of one major coronary artery branch (one vessel disease). The remaining 5 patients had more than 85 per cent stenosis of two major coronary artery branches (two vessel disease). Pathological $Q$ waves in the electrocardiogram indicating anterior myocardial infarction were found in 8 patients; 5 other patients had pathological $Q$ waves indicating inferior myocardial infarction. The remaining 7 patients had no pathological $Q$ waves. All patients had at least one asynergic hemiaxis in the control ventriculogram. This group had a second ventriculogram after nitroglycerin administration.

(3) Group 3 consisted of 25 patients with ischaemic heart disease. There were 2 women and 23 men with a mean age of $48.7 \pm 7.9$ years. Eleven patients had one, 9 patients had two, and 5 patients had three vessel disease (as defined). Pathological $Q$ waves in the electrocardiogram were found in 12 patients (anterior infarction 8 , inferior infarction 4). The remaining 13 patients showed no pathological $Q$ waves. Of 25 patients, 23 had at least one asynergic hemiaxis in the control ventriculogram. This group had a second ventriculogram after rapid ventricular pacing.

\section{Design of study}

Before the injection of any contrast material, heart rate, and left ventricular and aortic pressures were recorded (via femoral artery) using a Statham $\mathrm{P} 23 \mathrm{Db}$ pressure transducer at midchest position. In mid-inspiration (right anterior oblique position) $40-50 \mathrm{ml}$ of Urografin 76 (meglumine amidotrizoate and $\mathrm{Na}$-amidotrizoate) were injected over a period of 2 to 3 seconds with a power syringe, while cineangiograms were exposed at 32 frames/s on $35 \mathrm{~mm}$ film. During this injection the electrocardiogram was recorded continuously. Thereafter coronary cinearteriography was performed using selective injections in the right and the left coronary arterial system in several right and left anterior oblique views. After the last angiogram a period of 15 to 20 minutes was allowed to elapse for dissipation of the effects of contrast material. After the waiting period left ventricular pressures were again recorded. When left ventricular end-diastolic pressure had returned to control levels, nitroglycerin $1.6 \mathrm{mg}$ sublingually was given to patients in groups 1 and 2 . This resulted in a decrease of left ventricular systolic pressure and left ventricular end-diastolic pressure (usually after $5 \mathrm{~min}$ ). Thereafter ventriculography was repeated.

Patients in group 3 had a bipolar pacing electrode placed into the apex of the right ventricle (via femoral vein) 15 minutes after the control ventriculogram. After recording left ventricular pressures, ventricular pacing was started with a pacing rate of $120 \mathrm{bpm}$ and was gradually increased to a maximum of $180 \mathrm{bpm}$. Maximal pacing rate was maintained for 1 minute. Left ventricular enddiastolic and systolic pressures were recorded continuously until 20 seconds after pacing had stopped. After a second resting period of at least 5 minutes pacing was repeated and 2 seconds after stopping the pacing a second ventriculogram was obtained.

\section{Angiocardiographic methods}

Quantitative ventriculography was carried out using a sphere calibration technique and the area length method (Sandler and Dodge, 1968). Enddiastolic and end-systolic volumes were derived from the largest and smallest silhouettes, using the apex and the aortic root as reference points. Ventriculographic images selected for analysis were taken from the first four sinus beats after injection of contrast material. In addition, in 57 of 76 patients a single postextrasystolic beat during control ventriculography was analysed. In 8 patients in group 3 a single postextrasystolic beat during 'ischaemic ventriculography' (after pacing) was also analysed. In all postextrasystolic beats the compensatory pause, as measured from the electrocardiogram, was more than one and a half of the cycle length of normal sinus intervals. To assess total ventricular function, end-diastolic and endsystolic volumes (EDV, ESV) and ejection fractions $\left(E F=\frac{E D V-E S V}{E D V} \times 100 \%\right)$ were determined. No regression equation was used to correct for 'true' volumes. To quantify regional ventricular function further, a long axis (L) was drawn from the aortic root to the apex for each end-diastolic and endsystolic silhouette. This axis was divided into 

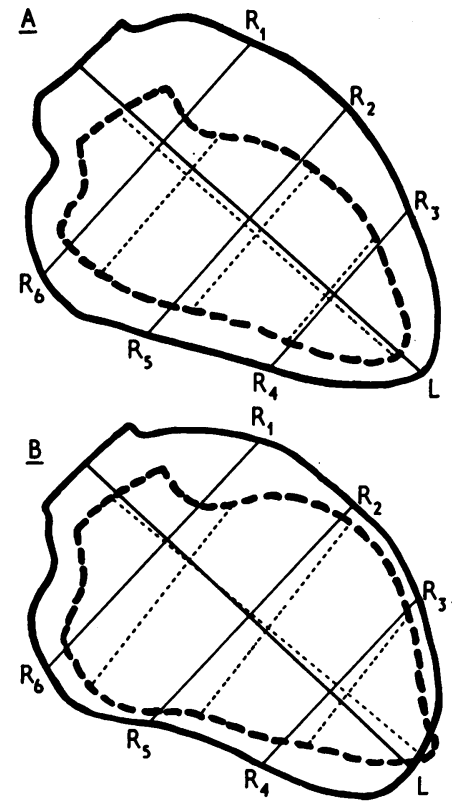

Fig. 1 End-diastolic and end-systolic silhouettes are shown during control beat $(A)$ and during ischaemic beat $(B)$. The hemiaxes during end-diastole and end-systole are traced. It is evident that a theoretical centre of the end-diastolic and end-systolic area is assumed. These centres are not identical, but become superimposed in the calculations.

hemiaxes by a perpendicular line at the midpoint and perpendicular lines were drawn at the midpoints of these hemiaxes. These perpendicular lines from the long axis to the endocardial surface were called hemiaxes $\mathbf{R}_{\mathbf{1}}-\mathbf{R}_{\mathbf{6}}$ (Fig. 1). The long axis was taken as one axis only, because the aortic root does not contract. The percentage shortening of each axis with systole was determined as diastolic axis minus systolic axis, divided by the diastolic axis. The lower limits of hemiaxes shortening (mean value minus 2 standard deviations) of group 1 (normal ventricles) are depicted in Fig. 2 (lower panel, control beat dotted lines) and are as follows: $R_{1}=22$ per cent; $R_{2}=22$ per cent; $R_{3}=14$ per cent; $R_{4}=20$ per cent; $R_{5}=15$ per cent; $R_{6}=12$ per cent; $\mathrm{L}=11$ per cent. Hemiaxes which had less shortening than these lower limits were defined as asynergic. Statistical significance was accepted at the 5 per cent probability level when using the Student's $t$ test for paired and unpaired data.

\section{Results}

(A) TOTAL VENTRICULAR FUNCTION

Patients with ischaemic heart disease showed abnormal ventricular function as compared to the

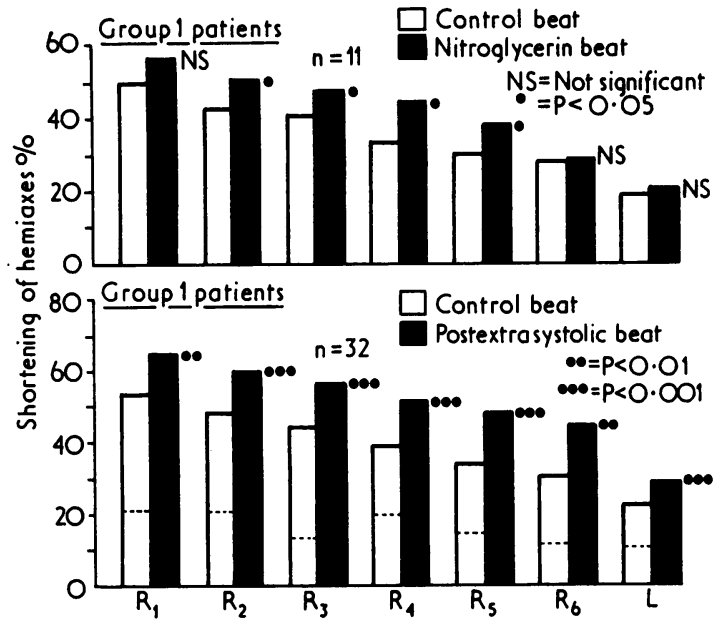

Fig. 2 Mean values of shortening of hemiaxes are given during control and nitroglycerin beat (upper panel) and during control and postextrasystolic beat (lower panel). Dotted lines in the lower panel mark lower normal limits of shortening of hemiaxes (mean value minus $2 S D$ ).

group 1 controls. End-diastolic pressure was significantly raised $(P<0.001$ for groups 2 and 3$)$, end-diastolic and end-systolic volume was raised $(P<0.001$ for groups 2 and 3), and ejection fraction was reduced ( $P<0.001$ for groups 2 and 3, Table). The small differences between the 3 groups for heart rate and left ventricular systolic pressure were not statistically different $(P>0.05)$.

\section{Response to nitroglycerin}

In the control patients (group 1) nitroglycerin produced a significant fall in left ventricular systolic pressure $(P<0.05$, for sets of paired observations) and left ventricular end-diastolic pressure $(P<0.01$, Table). Heart rate $(P<0.01)$, and ejection fraction increased slightly $(P<0.01)$. In ischaemic heart disease (group 2) left ventricular systolic pressure $(P<0.001$, for sets of paired observations), and left ventricular end-diastolic pressure decreased significantly $(P<0.001)$. Heart rate remained unchanged while ejection fraction decreased slightly but significantly $(P<0.05$, Table). The change in the ejection fraction in group 2 was significantly different from that in the normal ventricles $(P<0.001$, Table).

\section{Response to postextrasystolic potentiation}

In the normal controls (group 1) a single postextrasystolic beat induced an increase in ejection fraction of 11.2 per cent $(P<0.001$, if comparing sets of paired observations). In patients with left ventricular asynergy ejection fraction increased 
Table Haemodynamic and angiographic results of study (mean values \pm standard deviations (SD) of 3 groups studied)

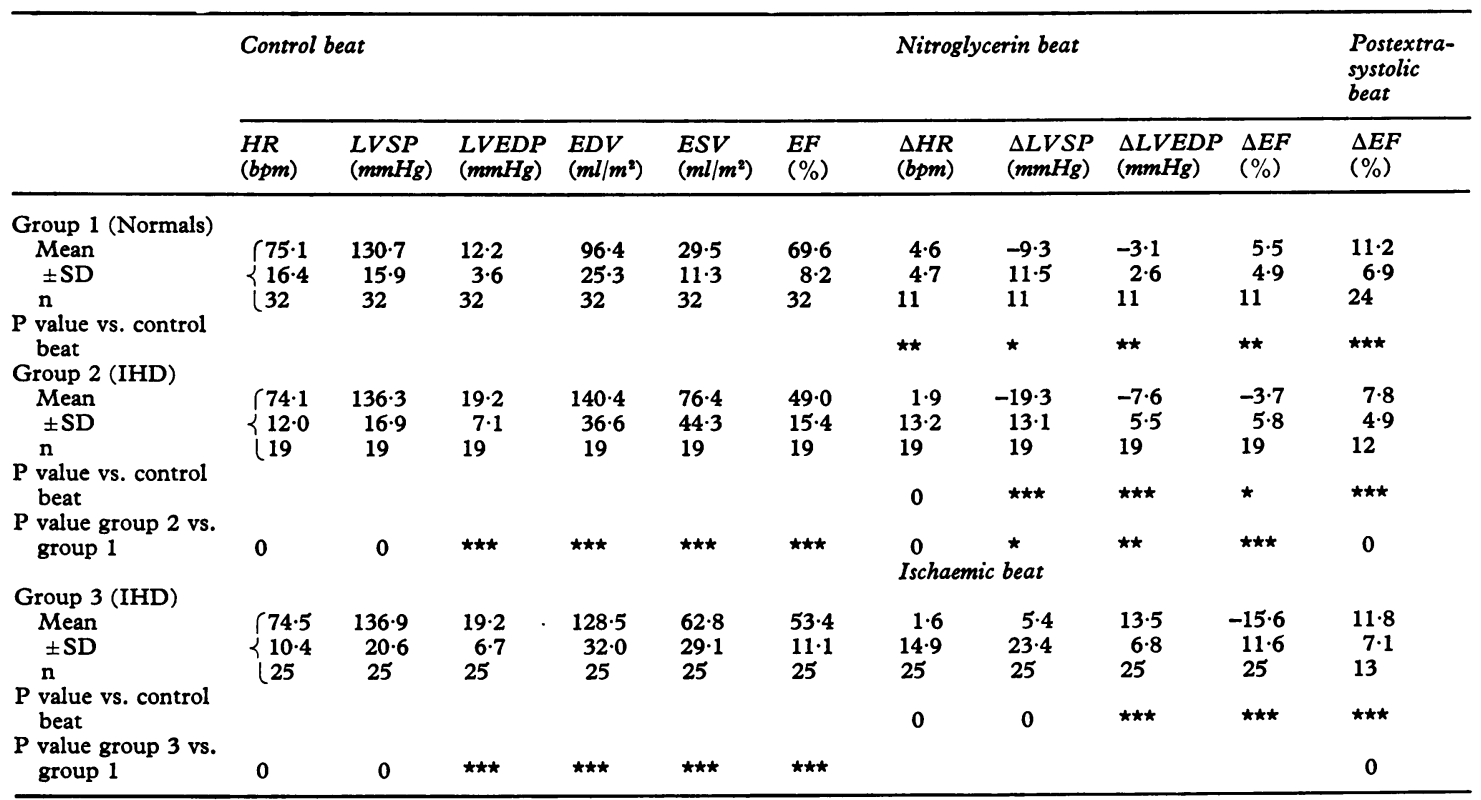

EDV, end-diastolic volume; ESV, end-systolic volume; EF, ejection fraction; $\triangle E F$, change of EF after an intervention; HR, heart rate, $\triangle H R$ change of $H R$ after an intervention; IHD, ischaemic heart disease; LVEDP, left ventricular end-diastolic pressure; $L V S P$, left ventricular systolic pressure; $\triangle \mathrm{LVEDP}$, change of LVEDP after an intervention; $\triangle \mathrm{LVSP}$, change of LVSP after an intervention; 0 , not significant $\star P<0.05 ; \star \star P<0.01 ; \star \star \star P<0.001$.

after a premature beat by $7 \cdot 8$ per cent (group 2 ) and by 11.8 per cent (group $3, \mathrm{P}<0.001$, for sets of paired observations). These changes are comparable to the response in normal ventricles $(P>0.05$, Table).

\section{Response to rapid ventricular pacing}

Immediately after rapid ventricular pacing had been stopped, heart rate and left ventricular systolic pressure were comparable to control conditions ( $P>0.05$, if comparing sets of paired observations). End-diastolic pressure increased $13.5 \mathrm{mmHg}$ $(P<0.001)$ and ejection fraction fell 15.6 per cent $(\mathrm{P}<0.001$, Table).

\section{Response to postextrasystolic potentiation during pacing-induced ischaemia}

Postextrasystolic potentiation during pacing-induced ischaemia produced a rise of ejection fraction of 14.4 per cent if compared with the ischaemic beat ( $P<0.01$. for sets of paired observations).

\section{(B) REGIONAL VENTRICULAR FUNCTION Response to nitroglycerin}

After nitroglycerin, shortening of $\mathbf{R}_{2}-\mathbf{R}_{5}$ was increased in normal ventricles $(P<0.05$, for sets of paired observations, Fig. 2, upper panel).
Asynergic hemiaxes in ischaemic heart disease (group 2) remained unchanged after nitroglycerin ( $P>0.05$, for sets of paired observations, Fig. 3A). Asynergic hemiaxes with $Q$ waves in the electrocardiogram and hemiaxes without $Q$ waves showed no significant change $(P>0.05)$. Normal hemiaxes in ventricles with asynergy remained unchanged after nitroglycerin $(P>0.05$, Fig. 3B).

\section{Response to postextrasystolic potentiation}

Postextrasystolic potentiation homogeneously increased wall motion in normal ventricles as shown in Fig. 2, lower panel. Asynergic hemiaxes in ischaemic heart disease showed a significant increase of wall motion irrespective of the presence $(P<0.001)$ or absence of pathological $Q$ waves $(P<0.001$, Fig. 3C). Shortening was also increased in normal areas of diseased ventricles (Fig. 3D). The degree of improvement after premature beat was comparable in normal and asynergic areas $(P>0.05)$. Fig. 4A shows the regional contraction pattern in a patient with anterior asynergy. Anterior wall motion is reduced but not completely absent, while inferior wall motion' is normal. After premature beat anterior motion is enhanced. Normal wall motion without asynergy was found in another patient with 2 critical coronary stenoses (Fig. 4C). 


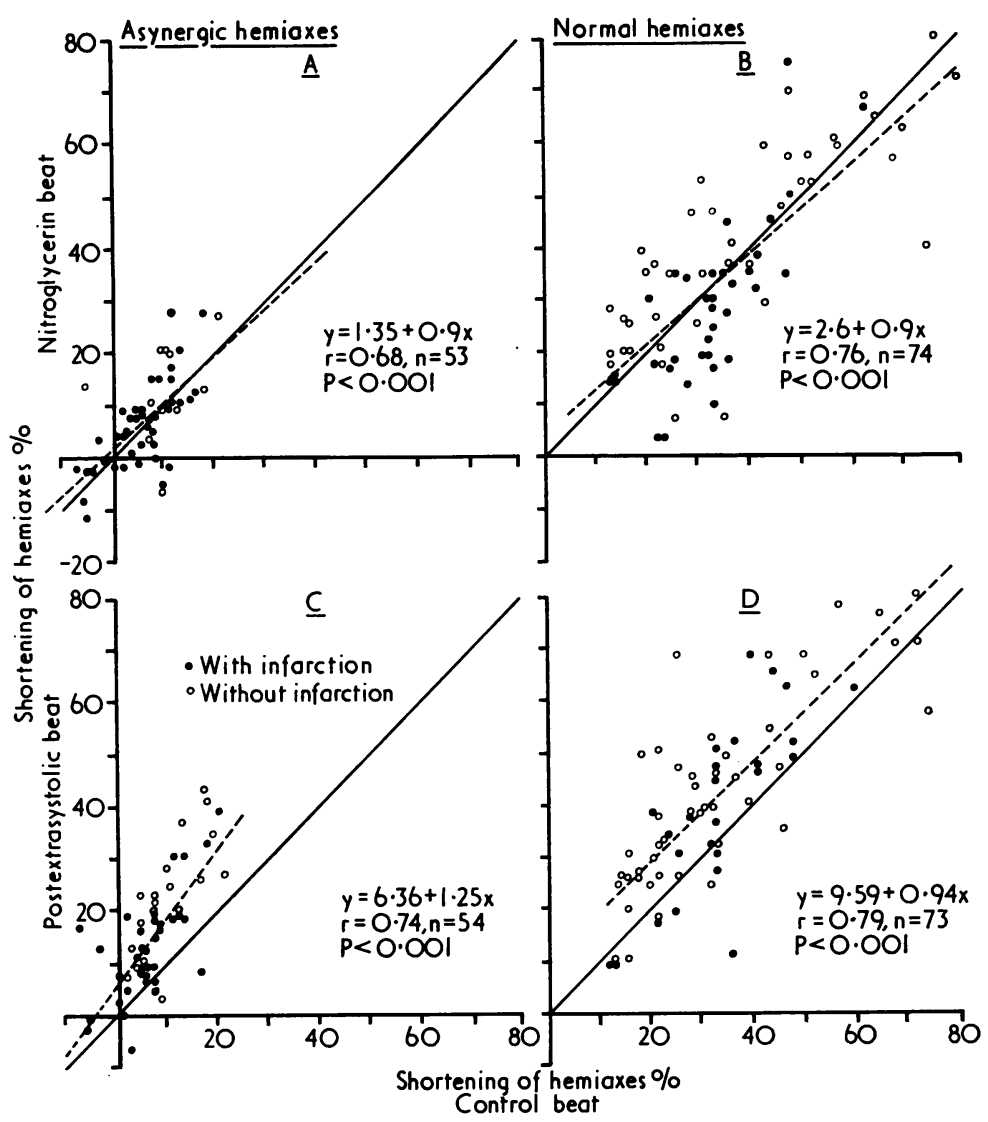

Fig. 3 All individual data of wall motion during control as compared with nitroglycerin (upper panels) and during control as compared with postextrasystolic potentiation (lower panels). Hemiaxes with and without myocardial infarction are separated.

After a premature beat a uniform increase of wall motion can be seen.

\section{Response to rapid ventricular pacing}

Rapid ventricular pacing did not change wall motion in already asynergic areas (see Fig. 5A) irrespective of the presence or absence of pathological $Q$ waves in the electrocardiogram $(P>0 \cdot 05)$. Normally contracting areas, however, supplied by arteries with critical coronary stenoses show a significant deterioration of wall motion $(P<0.001$, Fig. 5B). The majority of these areas had no related pathological $\mathbf{Q}$ waves in the electrocardiogram. Normal hemiaxes without coronary stenoses remained unchanged during pacing-induced ischaemia $(\mathbf{P}>$ 0.05 , for sets of paired observations). In Fig. 1 left ventriculograms before and after pacing are shown in a patient with critical obstruction of the anterior descending branch of the left and of the main branch of the right coronary artery. Reduced anterior and inferior wall motion is seen in the ischaemic ventriculogram (B) as compared with the control (A). Massive deterioration of normal anterior wall motion is seen in a patient with twovessel disease, while only moderate impairment occurred in the posterior wall (Fig. 4C). Fig. 4B shows a marked depression of wall motion in a ventricle with anterior asynergy, while no further deterioration of anterior asynergy was seen in another patient after pacing (Fig. 4D).

\section{Response to postextrasystolic potentiation during} pacing-induced ischaemia

Postextrasystolic potentiation restored wall motion after pacing-induced ischaemia: normal areas which became depressed during ischaemia reached control levels again after postextrasystolic potentiation $(P<0.05)$. A typical example is shown in Fig. 4B: the dramatic reduction of wall motion after pacing is offset after premature beat. Asynergic areas, however, again remained unchanged and showed the same shortening as in control $(P>0.05)$. 


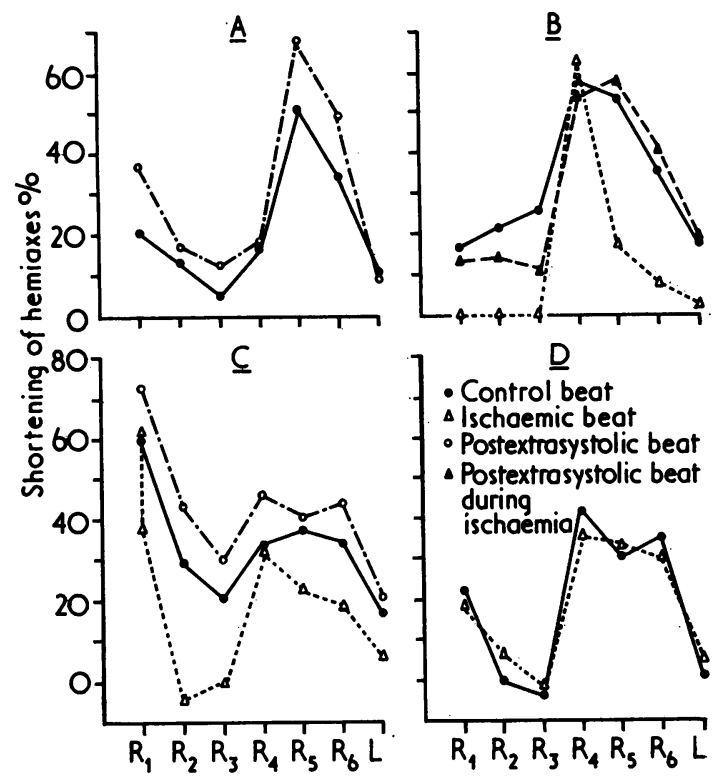

Fig. 4 Individual data for shortening of hemiaxes of 4 patients with ischaemic heart disease are given. Depicted are 4 different conditions : control, postextrasystolic potentiation, pacing induced acute ischaemia, and postextrasystolic potentiation during acute ischaemia.

\section{Discussion}

Some methodological problems of the study of ventricular volumes and regional contraction patterns in man need discussion. First of all, it has to be recognised that the injection of contrast materials into the left ventricle produces a temporary depression of cardiac function which is accompanied by an increase of end-diastolic pressure, end-diastolic and end-systolic volume (Rahimtoola et al., 1970; Shubrooks et al., 1975). Haemodynamic changes reach control levels again after 15 minutes (Mullins et al., 1972; Gootman et al., 1970). Therefore we allowed 15 to 20 minutes as a period of rest before the second ventriculogram. Another problem is the measurement of volumes from single plane angiograms. Cohn et al. (1974) showed a good correlation in patients with asynergy between single plane and biplane angiograms, with the exception of few cases. The motion of the posterolateral segment in particular, can be misinterpreted as outlined by Helfant et al. (1974). We, therefore, excluded all patients with isolated disease of the circumflex branch of the left coronary artery. Evaluation of regional wall motion was done by the use of hemiaxes. We superimposed the long axis and the axis bisecting the long axis, thereby marking a theoretical centre of the left ventricle. Since exactly the same technique and positioning were used for ventriculography before and after an intervention errors should have minimal influence on the interpretation of results.

Nitroglycerin produced an increase in ejection fraction in normal ventricles. This was the result of increased shortening of hemiaxes $R_{2}-R_{5}$. However, shortening of the long axis and the hemiaxes near the base of the left ventricle remained unchanged. Similar results were obtained in the dog heart by cineangiography after application of nitroglycerin intravenously: Liedtke et al. (1972) found that shortening of the long axis and the diameter at the base of the left ventricle remained unchanged,

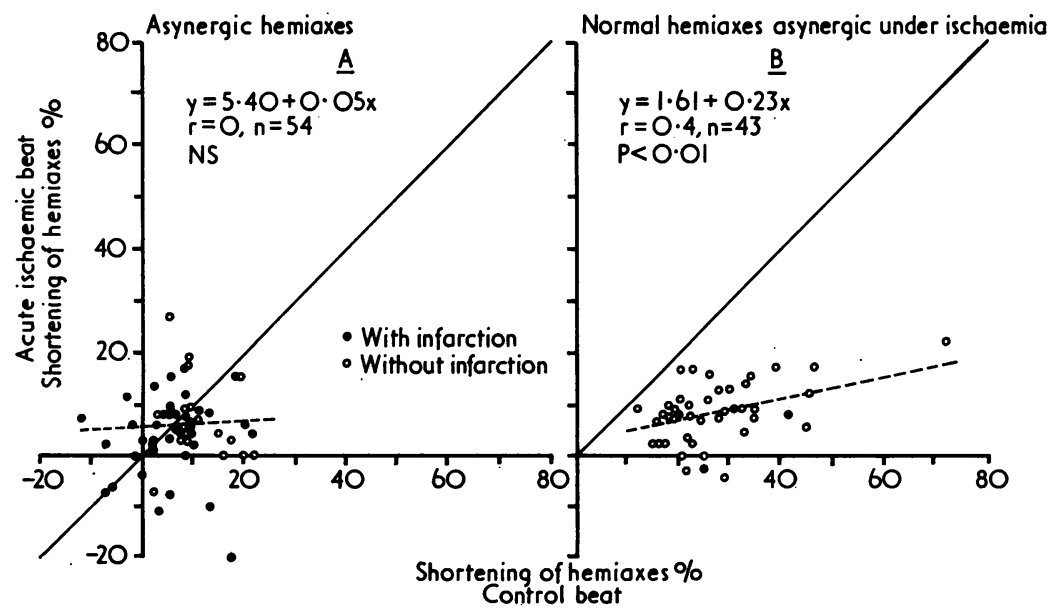

Fig. 5 The individual data for shortening of hemiaxes during control as compared with acute ischaemia. Hemiaxes with and without myocardial infarction are separated. 
while shortening near the apex increased significantly from 38 to 48 per cent. They attributed this change of contraction pattern to the decrease of afterload which follows application of nitroglycerin.

The response of asynergic ventricles to nitroglycerin is totally different from normal ventricles. The ejection fraction did not improve after nitroglycerin as compared with control. Asynergic hemiaxes remained unchanged as well as normal hemiaxes in patients with ventricular asynergy. It is necessary to consider whether the evaluation of wall motion abnormalities may be influenced by the definition used for asynergy. McAnulty et al. (1975) defined asynergy by 'visual inspection' and Helfant et al. (1974) defined hypokinesis as 'diminished contraction'. Both these studies gave no quantitative analysis as was done in the present study. Comparison of their results with the present ones is, therefore, difficult. McAnulty et al. (1975) found two groups of patients with coronary artery disease which responded differently to nitroglycerin. One group with only slightly increased enddiastolic volumes $(+19 \%)$ showed an increase of ejection fraction after nitroglycerin. The second group with more dilated ventricles $(+61 \%)$ showed no change of ejection fraction. Our group which was analysed after nitroglycerin is similar to this second group. Obviously the end-diastolic size of the left ventricle influences the changes induced by nitroglycerin. Helfant et al. (1974) found improvement in 73 per cent of hypokinetic zones, and in 57 per cent of akinetic zones after nitroglycerin. Sniderman et al. (1974) investigating 7 hypokinetic segments found normalisation in 3, no change in 2, and dyskinesis in 2 other segments. Bardfeld and Spindola-Franco (1976) reported a fall of ejection fraction after nitroglycerin in 2 of 5 patients with ischaemic heart disease; in addition 3 of 7 hypokinetic zones became akinetic, and 2 of 7 akinetic zones became dyskinetic. Apparently no uniform response of wall motion exists after nitroglycerin in ventricular asynergy. This is not surprising considering that even normal ventricles do not change uniformly after nitroglycerin. In addition, it is important to note that the size of the left ventricle modifies the response to nitroglycerin. Furthermore it cannot be excluded that improvement of wall motion after nitroglycerin as reported by other investigators (Helfant et al., 1974; McAnulty et al., 1975) may be the result of misinterpretation, since asynergy during control ventriculography was defined by subjective impression only. These conflicting data and our results confirm the opinion that nitroglycerin is not suited for diagnosis of reversibility of left ventricular asynergy.

After a single postextrasystolic beat, ejection fraction was significantly increased in all 3 groups about the same magnitude. Normal ventricles showed a uniform and powerful increase of hemiaxes shortening. Asynergic hemiaxes and normal hemiaxes in diseased ventricles increased shortening about the same extent. Our quantitative changes of total and segmental ventricular function after postextrasystolic potentiation are similar to those reported by other investigators (Dyke et al., 1974; Hamby et al., 1975). The response of normal as well as asynergic ventricles to postextrasystolic potentiation is uniform and differs clearly from the response to nitroglycerin.

Rapid ventricular pacing induced myocardial ischaemia in patients with coronary artery disease as shown by the increase in left ventricular enddiastolic pressure and the pronounced fall of ejection fraction. Asynergic areas and areas supplied by normal arteries remained unchanged during ischaemia. Normally contracting areas, however, supplied by arteries with critical stenoses showed dramatic reduction of wall motion during ischaemia. The fact that contraction of normal muscle is severely depressed but not completely abolished during acute ischaemia is well known from animal experiments (Tennant and Wiggers, 1935; Harley et al., 1968; Hood et al., 1969; Bishop et al., 1974; Lekven and Kiil, 1975). Restoration of blood flow within one hour after acute experimental coronary artery occlusion repaired contractile function completely (Banka et al., 1974). In patients with acute ischaemia (impending myocardial infarction) successful bypass surgery restored abnormal wall motion in several cases (Favaloro et al., 1971). This shows that depression of wall force in acute ischaemia is a result of underperfusion and is reversible if reperfusion is established within one hour.

In discussing the problem of 'chronic ischaemia' of heart muscle it is necessary to appreciate that this term was proposed as an explanation for the fact that asynergic areas without infarction had improved wall motion after successful bypass surgery (Chatterjee et al., 1973). The term was derived by analogy from the situation in acute ischaemia which is associated with reversible asynergy. It was assumed that asynergy persists for a longer time in chronic ischaemia but that muscle remains viable. Horn et al. (1974), however, suggested that a mixture of scar tissue interspersed with normal heart muscle might present asynergy in several cases. Our results confirm the assumption that normal muscle exists in asynergic areas because a normal increase of shortening after postextrasystolic potentiation was found. In addition this muscle does not show further depression during pacing-induced ischaemia which would be expected 
if this muscle were chronically underperfused. The conclusion is allowed that the remaining muscle in asynergic areas often has normal contractile behaviour during control and even under stress conditions. This is indirect evidence that the surviving muscle in asynergic areas is normally perfused. Ventricular asynergy then may be interpreted as a quantitative problem; the amount of working muscle is diminished as a consequence of tissue loss, therefore contraction is weak.

Postextrasystolic potentiation restored wall motion in acute ischaemic areas. Other investigators found that under experimental conditions positive inotropic interventions increased wall force in acute ischaemic areas (Hood et al., 1969; Schelbert et al., 1971; Dyke et al. 1975).

No differences were found between asynergic areas associated with and without pathological $Q$ waves after nitroglycerin, postextrasystolic potentiation, and acute ischaemia. Normal hemiaxes which became acutely ischaemic rarely had pathological $Q$ waves.

The findings after aortocoronary bypass surgery confirm our results. Asynergy as a consequence of acute myocardial ischaemia (impending infarction) seems to improve after surgery (Favaloro et al., 1971; Chatterjee et al., 1972; 1973; Hamby et al., 1974). It is obvious that patients with an acute deterioration of wall motion after pacing are optimal candidates for bypass surgery. Evidence for critical luminal narrowing which impedes flow during stress is given by the acute depression of wall motion.

Asynergy, however, not caused by acute ischaemia is not expected to improve after bypass surgery since there is not enough evidence that asynergy is caused by lack of blood flow. Our conclusion is in accordance with the results after bypass surgery which showed no consistent improvement of asynergy not caused by acute ischaemia (Bolooki et al., 1973; Shepherd et al., 1974; Achuff et al., 1975).

\section{References}

Achuff, S. C., Griffith, L. S. C., Conti, C. R., Humphries, J. O., Brawley, R. K., Gott, V. L., and Ross, R. S. (1975). The 'angina-producing' myocardial segment: an approach to the interpretation of results of coronary bypass surgery. American fournal of Cardiology, 36, 723.

Banka, V. S., Bodenheimer, M. M., Shah, R., and Helfant, R. H. (1975). The comparative usefulness of the nitroglycerin and postextrasystolic ventriculogram in unmasking reversible asynergy. Circulation, 51 and 52, Suppl. II, 11-36.

Banka, V. S., Chadda, K. D., and Helfant, R. H. (1974). Limitations of myocardial revascularisation in restoration of regional contraction abnormalities produced by coronary occlusion. American fournal of Cardiology, 34, 164.
Bardfeld, P. A., and Spindola-Franco, H. (1976). Paradoxical effect of nitroglycerin on left ventricular wall motion in coronary artery disease (abstract). American fournal of Cardiology, 37, 127.

Bishop, V. S., Kaspar, R. L., Barnes, G. E., and Kardon, M. B. (1974). Left ventricular function during acute regional myocardial ischaemia in the conscious dog. fournal of Applied Physiology, 37, 785.

Bolooki, H., Mallon, S., Ghahramani, A., Sommer, L., Vargas, A., Slavin, D., and Kaiser, G. A. (1973). Objective assessment of the effect of aortocoronary bypass operation on cardiac function. Fournal of Thoracic and Cardiovascular Surgery, 66, 916.

Chatterjee, K., Swan, H. J. C., Parmley, W. W., Sustaita, H., Marcus, H. S., and Matloff, J. (1973). Influence of direct myocardial revascularisation on left ventricular asynergy and function in patients with coronary heart disease. Circulation, 47, 276.

Chatterjee, K., Swan, H. J. C., Sustaita, H., Marcus, H., Matloff, J., and Parmley, W. W. (1972). Depression of left ventricular function due to acute myocardial ischemia and its reversal after aortocoronary saphenous vein bypass. New England fournal of Medicine, 286, 1117.

Cohn, P. F., Gorlin, R., Adams, D. F., Chahine, R. A., Vokonas, P. S., and Herman, M. V. (1974). Comparison of biplane and single plane left ventriculograms in patients with coronary artery disease. American fournal of Cardio$\log y, 33,1$.

Dyke, S. H., Cohn, P. F., Gorlin, R., and Sonnenblick, E. H. (1974). Detection of residual myocardial function in coronary artery disease using post-extrasystolic potentiation. Circulation, 50, 694.

Dyke, S. H., Urschel, C. W., Sonnenblick, E. H., Gorlin, R., and Cohn, P. F. (1975). Detection of latent function in acutely ischemic myocardium in the dog. Comparison of pharmacologic inotropic stimulation and post-extrasystolic potentiation. Circulation Research, 36, 490.

Favaloro, R. C., Effler, D. B., Cheanvechai, C., Quint, R. A., and Sones, F. M., Jr. (1971). Acute coronary insufficiency (impending myocardial infarction and myocardial infarction). Surgical treatment by saphenous vein graft technique. American fournal of Cardiology, 28, 598.

Gootman, N., Rudolph, A. M., and Buckley, N. M. (1970). Effects of angiographic contrast media on cardiac function. American fournal of Cardiology, 25, 59.

Hamby, R. I., Aintablian, A., Wisoff, B. G., and Hartstein, M. L. (1975). Response of the left ventricle in coronary artery disease to post-extrasystolic potentiation. Circulation, $51,428$.

Hamby, R. I., Tabrah, F., Aintablian, A., Hartstein, M. L., and Wisoff, B. G. (1974). Left ventricular hemodynamics and contractile pattern after aorto-coronary bypass surgery. American Heart fournal, 88, 149.

Harley, A., Behar, V. S., and McIntosh, H. D. (1968). Immediate hemodynamic effects of acute coronary occlusion and their modification by anesthesia. American fournal of Cardiology, 22, 559.

Helfant, R. H., Pine, R., Meister, S. G., Feldman, M. S., Trout, R. G., and Banka, V. S. (1974). Nitroglycerin to unmask reversible asynergy. Correlation with post coronary bypass ventriculography. Circulation, 50, 108.

Hood, W. B., Covelli, V. H., Abelmann, W. H., and Norman, J. C. (1969). Persistance of contractile behaviour in acutely ischaemic myocardium. Cardiovascular Research, 3, 249.

Horn, H. R., Teichholz, L. E., Cohn, P. E., Herman, M. V., and Gorlin, R. (1974). Augmentation of left ventricular contraction pattern in coronary artery disease by an inotropic catecholamine. The epinephrine ventriculogram. Circulation, 49, 1063.

Klausner, S. C., Ratshin, R. A., Lappin, H. A., Chatterjee, 
K., and Parmley, W. W. (1975). Post-extrasystolic potentiation vs. nitroglycerin impedance reduction: comparison of induced changes in segmental ventricular contraction in patients with ischemic heart disease. Circulation, $\mathbf{5 1}$ and $\mathbf{5 2}$, Suppl. II, 11-203.

Lekven, J., and Kiil, F. (1975). Myocardial function in general and regional left ventricular ischaemia in dogs at control and high aortic blood pressure. Cardiovascular Research, 9, 373.

Liedtke, A. J., Pasternac, A., Sonnenblick, E. H., and Gorlin, R. (1972). Changes in canine ventricular dimensions with acute changes in preload and afterload. American fournal of Physiology, 223, 820-827.

McAnulty, J. H., Hattenhauer, M. T., Rösch, J., Kloster, F. E., and Rahimtoola, S. H. (1975). Improvement in left ventricular wall motion following nitroglycerin. Circulation, 51, 140.

Mullins, C. B., Leshin, S. J., Mierzwiak, D. S., Alsobrook, H. D., and Mitchell, J. H. (1972). Changes in left ventricular function produced by the injection of contrast media. American Heart fournal, 83, 373.

Rahimtoola, S. H., Gau, G. T., and Raphael, M. J. (1970). Cardiac performance after diagnostic coronary arteriography. Circulation, 41, 537.

Sandler, H., and Dodge, H. T. (1968). The use of single plane angiocardiograms for the calculation of left ventricular volume in man. American Heart fournal, 75, 325.

Schelbert, H. R., Covell, J. W., Burns, J. W., Maroko, P. R., and Ross, J., Jr. (1971). Observations on factors affecting local forces in the left ventricular wall during acute myocardial ischemia. Circulation Research, 29, 306.

Shepherd, R. L., Itscoitz, S. B., Glancy, D. L., Stinson, E. B., Reis, R. L., Olinger, G. N., Clark, C. E., and Epstein, S. E. (1974). Deterioration of myocardial function following aortocoronary bypass operation. Circulation, 49, 467.

Shubrooks, S. J., Zir, L. M., Dinsmore, R. E., and Harthorne, J. W. (1975). Left ventricular wall motion response to intravenous Propranolol. Circulation, 52, 124.

Sniderman, A. D., Herscovitch, P., Marpole, D., and Fallen, E. L. (1974). Restoration of regional wall motion by nitroglycerin therapy in patients with left ventricular asynergy. Chest, 66, 545 .

Tennant, R., and Wiggers, C. J. (1935). The effect of coronary occlusion on myocardial contraction. American fournal of Physiology, 112, 351.

Requests for reprints to Dr. F. Schwarz, KerckhoffKlinik, D-6350 Bad Nauheim, Benekestrasse 6-8, Germany. 